\title{
O CORPO NO TEATRO
}

\author{
Luis Alberto Brandão Santos \\ UFMG
}

\begin{abstract}
RESUMO
O teatro exige a presença de corpos. É necessário, no entanto, repensar a concepção de que o corpo, numa encenação, subordina-se à imagem, ou seja, a seu caráter explícito de representação; é necessário levar em conta que o contato de corpos no espaço cena-platéia não visa apenas a veicular uma convenção ficcional: há, no teatro, um excesso de corpo que transvaza da ficção. A relação entre ator e personagem é necessária - o teatro só existe através de um pacto ficcional —, mas nāo é suficiente - a significação do corpo do ator não se esgota no fato de ser personagem. Como pensar, então, as relaçōes entre as camadas de signos que agem no espaço teatral? Como se dá a semiose que torna possível uma ficção gerada pelo contato de corpos?
\end{abstract}

\footnotetext{
PALAVRAS-CHAVE

corpo, semiótica, teatro
}

Se tentamos esboçar uma definição dos elementos caracterizadores do evento teatral, deparamo-nos, de uma forma ou de outra, com um dado indispensável: a presença do corpo. Essa presença deve ser entendida segundo um duplo aspecto: diz respeito, por um lado, à presença do corpo do espectador, e, por outro, à presença do corpo do ator ou do elemento que atua.

Certamente, o sentido de corpo não se limita ao de corpo humano, apesar de abrangê-lo, já que diferentes tipos de objetos podem desempenhar papéis fundamentais no teatro, havendo mesmo encenações que chegam a dispensar o ator para explorar corporeidades não-humanas. $O$ sentido de atuação também não se restringe ao de movimento físico - há, desse ponto de vista, encenações estáticas. Atuação é entendida aqui como o processo de se gerar significação tendo-se o corpo - atores e/ou objetos como ponto de partida.

Podemos afirmar, assim, que o teatro define-se por uma espécie de atuação desempenhada por meio da presença de corpos em um contexto que visa à produção, à provocação de determinadas significações. De uma maneira geral, tal contexto é criado segundo dois critérios básicos: uma preocupação de caráter estético e um contrato de ficcionalidade - ficção transvazada aos corpos. Naturalmente, há propostas que avançam sobre os limites do estético e do ficcional. É o caso, por exemplo, do teatro invisível, ou de alguns tipos de performance que desejam uma intervenção direta no próprio quotidiano. 
Tais propostas, ao colocarem em xeque a definição do evento teatral, enfatizam exatamente a força de seus limites.

Inter-relação de corpos. Corpos que interagem no espaço da cena. Corpos que interagem no espaço da audiência. Corpos no palco interagindo com corpos na platéia. Mesmo que tais espaços sejam intercambiáveis, há sempre um jogo de mútua presencialidade dos corpos. E é através desse jogo que surge o para-além do corpo: sua ficcionalização. Tempo, espaço, ação: vetores inerentes ao vetor principal: o diálogo de corpos mediado por um "algo mais" de sentido: o caráter explícito de representação.

O objetivo deste texto é tentar descrever tal diálogo. A pergunta central poderia ser formulada da seguinte maneira: como se dá a semiose que aflora a partir do contato de corpos ficcionalizados? Ou: como se caracteriza uma ficção que se constrói por meio da presença dos corpos?

\section{A IMAGEM DO CORPO}

A resposta pode começar a ser esboçada a partir de duas passagens de Bergson:

Meu corpo é, portanto, no conjunto do mundo material, uma imagem que atua como outras imagens, recebendo e devolvendo movimento, com a única diferença, talvez, de que meu corpo parece escolher, em uma certa medida, a maneira de devolver o que recebe.'

Os objetos que cercam meu corpo refletem a ação possível de meu corpo sobre eles. ${ }^{2}$

Alguns aspectos podem, aqui, ser destacados e relacionados ao teatro. O primeiro deles é a potencialidade de escolha atribuída ao corpo. Como o teatro se dá na forma de um processo, ou seja, por meio de um desenvolvimento temporal, os corpos em cena apesar de um provável planejamento anterior - não perdem seu poder de escolha. Há, no teatro, a flexibilidade inerente à atuação do corpo que se move em um presente constantemente renovado. Por maiores que sejam as determinações prévias, um ator, ao realizar seu gesto, torna nova a escolha de dar impulso a um certo ato significativo. É isso que torna vital o elemento improvisação no teatro.

Quanto ao espectador, a escolha é exercida de diversas maneiras. Primeiramente, pelo simples fato de estar ali, expondo-se ao fluxo de signos gerados pelos corpos em cena. Em segundo lugar, pelo trabalho de seleção, assimilação e hierarquização dos signos que sua percepção opera. Finalmente, por adentrar na cadeia de significação, gerando hipóteses interpretativas para o conjunto de signos que o assedia.

Levando-se em conta o fator escolha, fica ressaltada, no teatro, certa independência entre o espaço da cena e o da audiência, que coexistem paralelamente. O primeiro motivo, óbvio, é que o teatro é uma atividade coletiva, não necessitando, portanto, de um receptor individual para gerar significação - é preciso lembrar, inclusive, que os atores são espectadores de si mesmos. O segundo motivo é que o corpo, no teatro, não funciona apenas como instrumento de veiculação de um dado convencional, que é a ficcionalidade, ou seja, o ator não é somente veículo da personagem. A significação do corpo, como

${ }^{1}$ BERGSON. Matéria e memória, p.11.

${ }^{2}$ IBIDEM. p. 12. 
corpo, coexiste com sua ficcionalidade, nāo estando subordinada a ela. O corpo do ator efetivamente veicula a idéia de personagem, mas excede tal idéia, isto é, o ator - corpo - coexiste com a personagem - imagem.

Paradoxalmente, essa independência produz um maior imbricamento entre cena/ audiência. Merleau-Ponty afirma que "as coisas imbricam-se umas nas outras porque estão uma fora da outra". ${ }^{3}$ Chega-se aqui ao segundo aspecto: a atuação mútua. Há, no teatro, não apenas o movimento que vai da cena até o espectador, mas um outro movimento, que vai do espectador para a cena. Assim, em função da presença dos corpos, a participação do espectador não consiste apenas em completar a cadeia de significação gerada pela obra-cena, pois se trata de uma participação que afeta a própria obra.

Se é inegável que o papel de qualquer leitor é sempre ativo, já que o sentido de um texto pressupõe sua recepção, é preciso lembrar que no teatro a atividade do leitorespectador pode ser, de uma forma ou de outra, absorvida pelo texto-cena, afetando, assim, o ponto de partida da produção do sentido. Desse modo, não apenas o sentido da obra modifica-se em função do espectador, mas a própria obra também se modifica. Esse efeito se dá em qualquer manifestação teatral, apesar de ser mais evidente em propostas nas quais a interferência do espectador é um dado previsto para o desenvolvimento da cena.

Quando Bergson fala de ação possível entre corpos e objetos, o sentido de "possível", no teatro, deve ser entendido dentro de um duplo desdobramento. Diz respeito à liberdade de ação - o fator independência mútua - e ao condicionamento da ação - o fator determinação mútua.

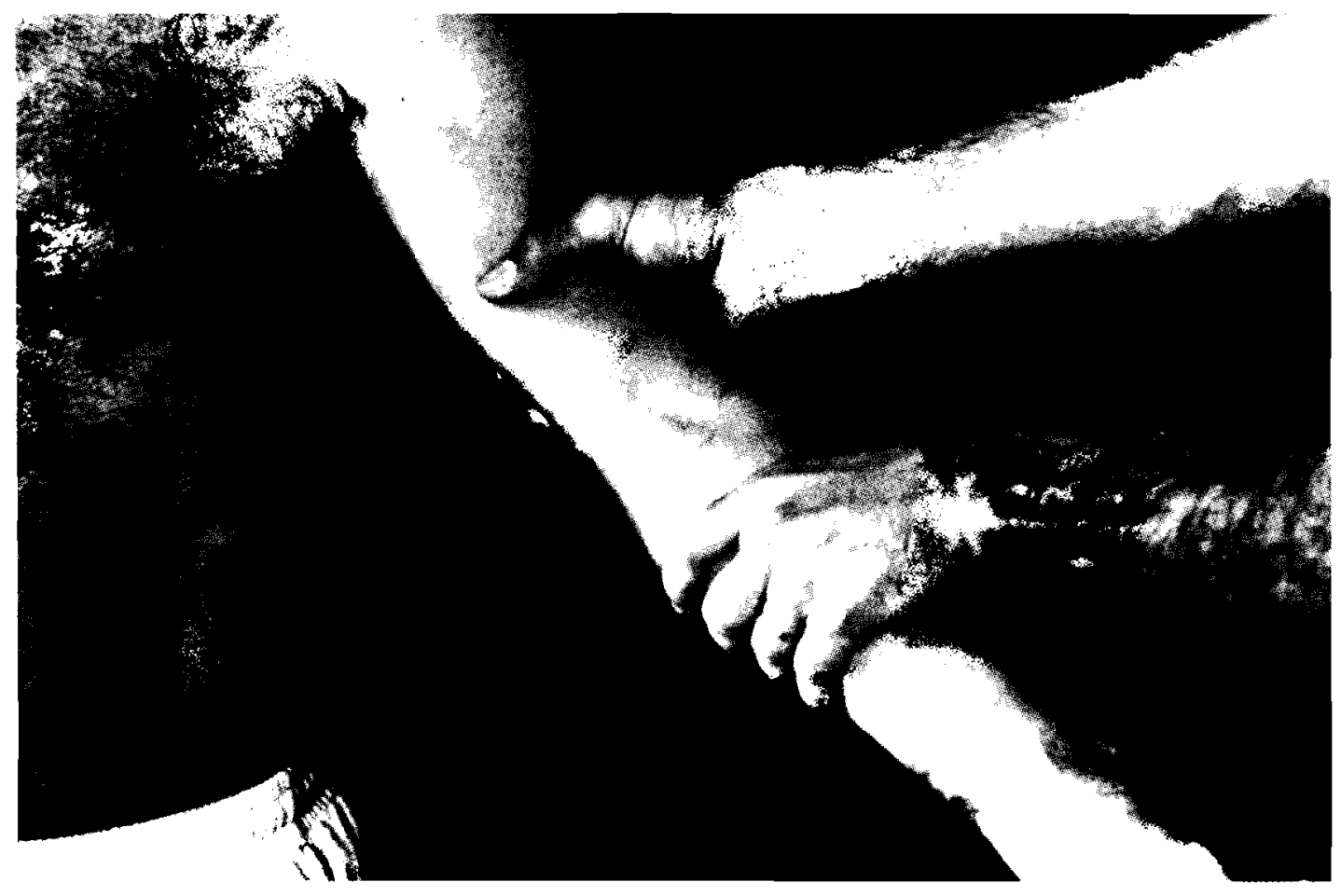

Ensaio de A rua da amargura, Grupo Galpão.

Foto de Gustavo Campos.

\footnotetext{
${ }^{3}$ Merleau-Ponty. O olho e o espírito, p.57.

${ }^{4}$ Pelrce. Semiótica, p.64.

${ }^{5}$ IBIDEM. p.64.
} 
Há ainda um terceiro aspecto: o corpo como imagem. Vale a pena, aqui, recorrer à concepção de imagem formulada por Peirce. Segundo ele, qualquer imagem material é um signo icônico de primeiridade. ${ }^{4}$ Dessa concepção, dois aspectos sobressaem. Peirce fala de signo icônico e não de ícone, o que aponta para o valor convencional da imagem. Por outro lado, ao situá-la em uma primeiridade, enfatiza seu caráter de expressão direta de uma qualidade. Nas palavras de Peirce: "A única maneira de comunicar diretamente uma idéia é através de um ícone". 5

Assim, para desenvolver a noção de corpo enquanto imagem, é preciso levar em conta seu caráter simbólico, terceiro, de representação, e seu caráter icônico, primeiro, de apresentação. Tomemos como exemplo o corpo de uma pessoa em um parque. Em termos de primeiridade, há um continuum no qual o corpo, o banco em que está sentada, a árvore a seu lado, o lago, a grama, o céu são apenas um conjunto de qualidades. Em termos de secundidade, esses objetos se diferenciam, revelando-se como entes individuais. No entanto, o verbo revelar já pressupōe um olhar observador: eis a terceiridade.

Evidencia-se que a visão, ou melhor, todos os sentidos humanos já são sistemas de signos, ou seja, mediaçōes. O que faz com que, ao olhar para a pessoa no parque, sejamos capazes de distinguir seu corpo do corpo da árvore é uma operação convencional do nosso olho. Contudo, é inegável que tal operação é inerente à percepção humana, é um processo sígnico imanente à própria noção de humanidade. Quando olhamos para um corpo, o que vemos é um conjunto de signos - o que nossos sentidos podem e/ou querem perceber. Mas se é somente a tais signos que estamos fadados a ter acesso, passamos a considerá-los como o "em si" do corpo, signos de si mesmos.

No evento teatral, a presença dos corpos é mediada por duas camadas de signos. Uma delas é a ficcionalidade, o propósito convencional que motiva e permite a atuação dos corpos. A segunda é a própria percepção dos corpos. No entanto, como se viu, as camadas não se fundem, ou seja, a percepção do corpo do ator não está subordinada à convenção da idéia de personagem, mas é coexistente, paralela a tal convenção. Já que - os signos convencionais que determinam a percepção são imanentes a ela, há no teatro a impressão de corpos apresentados em sua plena corporeidade: relação entre corpos imediatos. Daí o efeito de uma primeiridade que se impõe, e não apenas se sujeita, à terceiridade no teatro.

\section{PASSAgEM AO LIMITE}

Dessa imposição surgem os paradoxos do teatro: presença-ausência, proximidadedistância, liberdade-condicionamento, afecção-percepção, apresentação-representação, icônico-simbólico. Propondo a presença dos corpos em um espaço-tempo simultaneamente único e múltiplo, o teatro propicia a experiência de se deslizar de um termo a outro de tais paradoxos. O deslizamento pode ser ilustrado pela seguinte passagem de Bergson:

A distância que separa nosso corpo de um objeto percebido mede portanto efetivamente a maior ou menor iminência de um perigo, o prazo maior ou menor de uma promessa. E, por conseqüência, nossa percepção de um objeto distinto de

\footnotetext{
${ }^{4}$ Peirce. Semiótica, p.64.

${ }^{5}$ IBIDEM. p.64.
} 
nosso corpo, separado de nosso corpo por um intervalo, nunca exprime mais do que uma ação virtual. Porém, quanto mais diminui a distância entre esse objeto e nosso corpo, tanto mais o perigo torna-se urgente ou a promessa imediata, tanto mais a ação virtual tende a se transformar em ação real. Passemos agora ao limite, suponhamos que a distância se torne nula, ou seja, que o objeto a perceber coincida com nosso corpo, enfim, que nosso próprio corpo seja o objeto a perceber. Então não é mais uma ação virtual, nas uma ação real que essa percepção muito particular irá exprimir: a afecção consiste exatamente nisso. ${ }^{6}$

teatro faz uso dessa promessa de passagem ao limite, de oscilação entre ação virtual e real sobre o corpo do espectador. A imagem-corpo do teatro requer, do espectador, prontidão de todos os sentidos. Por isso é possível encontrar em diversos autores, como em Roland Barthes, referências ao caráter erótico do teatro:

A função erótica do teatro não é acessória, porque só o teatro, dentre todas as artes figurativas (cinema, pintura), dá os corpos e não sua representação. $O$ corpo de teatro é ao mesmo tempo contingente e essencial: essencial, nāo pode ser possuído (ele é magnificado pelo prestígio do desejo nostálgico); contingente, poderia sê-lo, pois bastaria ficarmos loucos por um momento (o que está dentro de nossas possibilidades), pular para o palco e tocar aquilo que desejamos. ${ }^{7}$

No entanto, a noção de "tocar" pode ser pensada não apenas como um desejo possível, mas de um modo mais amplo. O tato nāo se limita à friç̧ão entre corpos. Podese pensar que há uma relação de toque estabelecida pelo simples fato de dois corpos estarem presentes em uma mesma sala, o ar e seus deslocamentos sendo elementos táteis que põem corpos em contato. Os sentidos humanos são regidos pela necessidade de contato direto - mediado, certamente, pela percepção - com os objetos. É por meio da aproximação física, cujos limites podem ser variáveis, que os sentidos atuam. Isso faz com que seja impossível isolar qualquer uma das funções sensoriais. É o que mostra, em relação à visão, Julio Plaza:

Pela própria complexidade do mundo perceptivo, do qual o canal visual é apenas uma parte, as experiências espaciais tornam-se tão interligadas ao sentido tátil que os dois sentidos não podem ser separados: olho e tato se contêm mutuamente. Tal separação é meramente cultural. ${ }^{8}$

O teatro se apresenta como espaço privilegiado para que as significações transitem mediante a integração de todos os sentidos. Daí seu amplo caráter sensorial. Daí a irredutibilidade de sua primeiridade, do seu jorro de qualidades, à terceiridade do seu aspecto de representação. Daí se derivam propostas, como a de Antonin Artaud, de um teatro que, "varrendo todas nossas representações, nos insufle o magnetismo ardoroso das imagens", provocando "esta espécie de picada concreta que comporta toda sensação verdadeira". ${ }^{10}$

A partir dessa perspectiva, torna-se necessário discordar de definições como a de Umberto Eco: "O signo teatral, porém, é fictício, não só porque se trata de um fingimento

\footnotetext{
${ }^{6}$ Bergson. Matéria e memória, p.41-2.

${ }^{7}$ BARTHEs. Roland Barthes por Roland Barthes, p.87.

${ }^{8}$ PlAzA. Tradução intersemiótica, p.57.

9 ARTaud. O teatro e seu duplo, p.109.

${ }^{10}$ IBIDEM. p. 110.
} 
ou de um signo que comunica coisas inexistentes (...), mas porque ele finge não ser um signo". ${ }^{11}$ Pensando-se dessa maneira, chega-se à conclusão redutora de que a presença do corpo teria por função apenas criar um "efeito de real", teria sempre uma pretensão ilusionista, ou seja, o objetivo seria meramente a simulação, com o corpo se sujeitando à ficção que ele deve veicular. Contraposta a essa concepção, está o fato de que, se é verdade que o signo teatral se afirma como fiç̧ão, também é indiscutível que se afirma como não-ficção, corpos que são signos de si mesmos. É dessa afirmação paradoxal, da coexistência de apresentação e representação - e não de um "fingir não ser o que é" que se alimenta o teatro. Pensar a ficcionalidade apenas como fingimento é não levar em conta que a ficção efetivamente cria realidades (todo texto cria um objeto; uma peça de teatro não é um objeto tão concreto quanto qualquer outro?); é ainda uma maneira de entender o processo de significação somente no seu caráter de referência, de signos que remetem a objetos externos a eles.

\section{OBJETOS POSSIVEIS}

A supervalorização da referência é encontrada mesmo quando se aponta para a iconicidade do teatro. O caráter icônico muitas vezes é entendido exclusivamente no sentido de analogia com um objeto anterior, ou seja, o signo referindo-se a um objeto determinado, reconhecível, com o qual possui alguma similaridade. No entanto, pelo menos em Peirce, é possível tomar o funcionamento do ícone de uma outra maneira: como aquele signo cujo objeto é indefinido. Nas palavras de Peirce: "O objeto de um ícone é absolutamente indefinido, equivalente a 'algo". ${ }^{12}$ Pode-se, ainda, pensar que o objeto é gerado pelo próprio signo: "O objeto de um signo pode ser algo a ser criado pelo signo". ${ }^{13}$ Tais concepções permitem deslocar a questão da analogia do plano da referência, sugerindo que o signo icônico opera não necessariamente com objetos de referência, mas com objetos possíveis.

Criação de objetos possíveis: eis talvez uma boa alternativa, em substituição ao "fingimento", para a caracterização da ficcionalidade. Pensar a significação apenas em termos de referência é pensar que o signo somente atua no sentido de repetir um objeto prévio. Toda linguagem se elabora, sem dúvida, através de um conjunto de referências, através de algum conhecimento. Mas toda linguagem também cria suas próprias referências, ou seja, constitui-se em conhecimento. É preciso, pois, pensar que o signo também instaura uma diferença, e, dessa forma, cria um objeto. Talvez a fiç̧ão seja um modo de gerar significação no qual a diferença não é remetida à repetição, o estranhamento nāo é subjugado pela familiaridade, a desordem não é aplainada em sistema.

No caso do teatro, o objeto possível criado pela ficção coexiste com o objeto concreto oferecido pela apresentação dos corpos. Portanto, há no teatro uma dupla coexistência: a diferença coexiste com a repetição — ou, em outras palavras, a criação coexiste com a referência -, e o virtual — o jogo de repetições e diferenças instaurado pela ficcionalidade - coexiste com o real - os corpos que se oferecem.

\footnotetext{
"Eco. Parâmetros da semiologia teatral, p.29.

${ }^{12}$ Peirce. Semiótica, p. 163.

${ }^{13}$ IBIDEM. p. 161.
} 
Há uma relação necessária entre ficção e realidade (entendida como referência externa): a ficção se constrói através de um conjunto anterior de saberes. Porém, não há uma relação suficiente: a ficção não se esgota nos objetos que cita pois cria outros objetos. Há uma relação necessária entre personagem - ficção - e ator — corpo — pois, no teatro, a personagem só existe através do corpo do ator: o teatro só existe através de um pacto ficcional. Contudo, não há uma relação suficiente, pois a significação do corpo do ator não se esgota no ser personagem: o teatro não se esgota no seu dado convencional.

O teatro é feito de excessos. Do excesso de primeiridade que transborda da terceiridade que a torna possível. Do excesso de um frescor e de uma novidade que respingam das bordas dos pactos convencionais. Do excesso de corpo que transvaza da ficção. Por propiciar tantos excessos e coexistências, o teatro torna possível uma experiência ímpar: fazer, com a luz que emana dos paradoxos, fulgurar a presença dos corpos.

\section{A}

\section{ABSTRACT}

Theater requires the presence of bodies. However, it's necessary to check the conception that body, in staging, is subordinated to image, to its explicit feature of representation; it's necessary to take into account that the contact of bodies in stage-audience space doesn't just intend to transmit a fictional convention: in theater, there is an excess of body that draws off fiction. The relationship between actor and character is necessary - theater only exists through a fictional pact - , but it's not sufficient the meaning of the actor's body is not limited to its being character. How to think the relationships between the layers of signs that actuate in theatrical space? How is the semiosis that makes a fiction created by the contact of bodies possible?

\section{KEY WORDS}

body, semiosis, theater

\section{REFERÊNCIAS BIBLIOGRÁFICAS}

ArTaud, Antonin. O teatro e seu duplo. Trad. Teixeira Coelho. São Paulo: Max Limonad, 1984.

Barthes, Roland. Roland Barthes por Roland Barthes. Trad. Leyla Perrone-Moisés. São Paulo: Cultrix, 1987.

Bergson, Henri. Matéria e memória. Trad. Paulo Neves da Silva. São Paulo: Martins Fontes, 1990.

Eco, Umberto. Parâmetros da semiologia teatral. In: Helbo, André (org.). Semiologia da representaçāo. São Paulo: Cultrix, 1980.

Merleau-Ponty, Maurice. O olho e o espírito. In: Textos selecionados. Trad. Marilena Chauí. São Paulo: Abril Cultural, 1980. Coleção Os Pensadores.

Peirce, Charles Sanders. Semiótica. Trad. Teixeira Coelho. São Paulo: Perspectiva, 1987.

PlazA, Julic. Traduçāo intersemiótica. São Paulo: Perspectiva, 1987. 